\title{
A method for measuring the amount of hoar frost formation in the recuperation channels of ventilation systems using the adjustable mathematical model of this process
}

\author{
Aleksandr Shilin ${ }^{1, *}$, Sergey Prokhorov ${ }^{1}$, Andrei Shabo ${ }^{1}$, and Viktor Bukreev ${ }^{1}$ \\ ${ }^{1}$ National Research Tomsk Polytechnic University, 634050 Tomsk, Russia
}

\begin{abstract}
The paper presents a method for measuring the amount of hoar frost formation in the recuperation channels of ventilation systems using the adjustable mathematical model of the hoar frost process. The principle is based on the fact that the contour of the adjustment of the hoar frost model is included in the measurement in accordance with the measured pressure drop, which is proportional to the amount of hoar frost. Unlike the known measurement methods, it is proposed to use the state variables of the mathematical model as the measured value. These state variables are not subject to non-deterministic interferences and random influences. The paper presents simulation results confirming the adequacy of the dynamic model. In conclusion, an example of the use of a recuperation channel in the defrost management system is given.
\end{abstract}

\section{Introduction}

The problem of frost formation in recuperation systems is known in many countries such as Russia, Canada and other northern countries, where the temperature of the environment can be below $-25 \circ \mathrm{C}$. The work [1] include the detail description of the hoar frost formation, dynamic processes, experimental data and many other features of such systems and other [2].

A several methods for solving this problem can be found in the works [3, 4], where it is proposed to add an additional heating element to the system, which defrosts the channel. The main problem of this method is providing the well-timed switching of modes to avoid the complete blockage of the channels. Switching time depend on the degree of hoar frost of the channel. The problem of switching time estimation are described in the works [5-7], where the problem of measuring the degree of hoar frost formation and its derivative is actual.

In this paper, a method is proposed for measuring this degree using a tunable mathematical model, where the variable states qualitatively reflect the process of dynamics.

\footnotetext{
Corresponding author: $\underline{\text { shilin@ } @ \text { tpu.ru }}$
} 


\section{The dynamic properties of process}

For the formation of state variables, a qualitative mathematical model of the process is required. To synthesize the model, we used the results of [8], which shows the results of mathematical modelling of the recuperation system and the results of experimental studies.

The mathematical model is created in the Xcos environment of the mathematical package SciLab on the functional blocks and is presented in Fig. 1 The model has the following blocks:

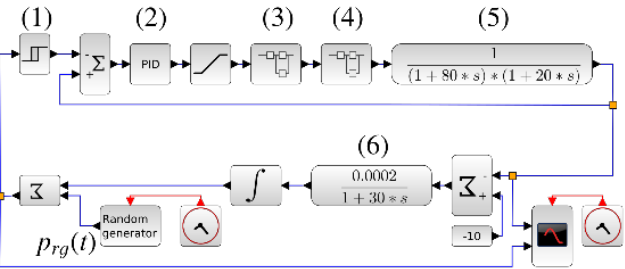

Fig. 1. Mathematical model of defrosting control in a recuperation system.
The recuperation system from Fig. 1

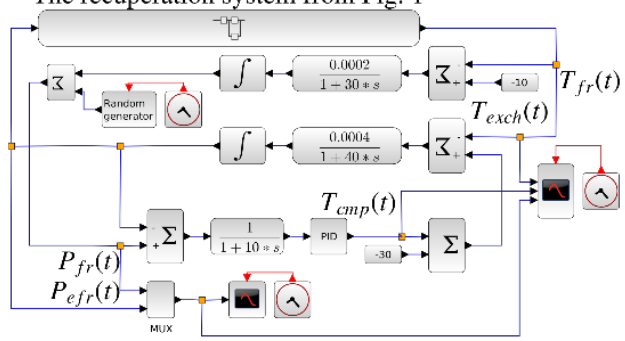

Fig. 2. Structural diagram with the observer of state variables.

Block 1: The Hysteresis element, designed to define the boundaries corresponding to the values of the layers at which the system will enter the defrost and frost operation mode, to provide the maximum efficiency mode. Block 2: PID-regulator, to maintain the modes. Block 3: The block of actuators "Frequency converter - Asynchronous motor". It is represented by a simplified differential equation in the form of a transfer function

$$
W_{a m}(s)=\frac{1}{\left(1+s T_{f t}\right)\left(1+s T_{a m 1}+s^{2} T_{a m 2}^{2}\right)}
$$

where time of the frequency transformer $\mathrm{T}_{\mathrm{ft}}=0.2 \mathrm{~s}$, times of Asynchronous motor $\mathrm{T}_{\mathrm{am} 1}=0.15 \mathrm{~s}$ and $\mathrm{T}^{2}{ }_{\mathrm{am} 2}=0.03 \mathrm{~s}$. The executive element of the system is a pump that ensures the circulation of the heat transfer medium between heat exchangers. This pump is made on the basis of an asynchronous motor. Since the transition process of hoar frost formation and defrosting is much slower than the processes in the engine itself. It is perfectly permissible to use aperiodic links of the first order as a mathematical dynamic model of the engine.

Block 4: The unit realizes the static connection from the control signal from the PID controller output in the "Frequency converter - Asynchronous motor", to the temperature at the output of the heat exchanger. In the block, the function proposed in [9] is implemented by expression:

$$
T_{\text {exch }}=T_{\text {room }}+\left(T_{\text {out }}-T_{\text {room }}\right) K_{\text {ef }} 0.1 U_{\text {pid }}
$$

where the room temperature $T_{\text {room }}=20{ }^{\circ} \mathrm{C}$, Ambient air temperature $T_{\text {out }}=-30{ }^{\circ} \mathrm{C}$; Efficiency coefficient of recuperator $\mathrm{K}_{\mathrm{ef}}, \mathrm{U}_{\mathrm{pid}} \in[0,10.0]$ - output value of PID-regulator.

Block 5: The link characterizing the process of increasing frost is represented by two successively connected inertial links of the first order, realizing the transfer function

$$
W_{\text {exch }}(s)=\frac{1}{\left(1+s T_{o 1}\right)\left(1+s T_{o 2}\right)}
$$

with time constants $\left(\mathrm{T}_{\mathrm{o} 1}=80 \mathrm{~s}\right)$ and $\left(\mathrm{T}_{\mathrm{o} 2}=20 \mathrm{~s}\right)$.

Block 6: The defrost process describes an aperiodic link of the first order with a time constant $\left(T_{o}=30 \mathrm{~s}\right)$ and a coefficient $\left(K_{p}=0.0002\right)$ proportional to the rate of increase in frost. 
The results of the simulation are presented in the form of transition process Fig. 3 $\left(p_{r g}(t)=0\right)$. From the processes it is clear that the model reflects the processes of growth and thawing of frost. The operation of the PID controller ensures that the temperature at the heat exchanger outlet is maintained in both modes. The form of the obtained transient processes was also confirmed by specialists servicing the system under investigation in Yakutia (Russia). However, in real conditions, due to the
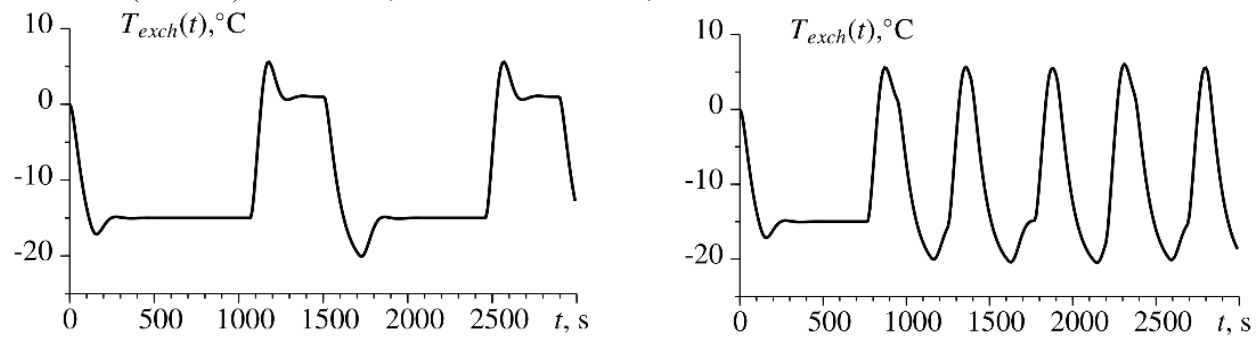

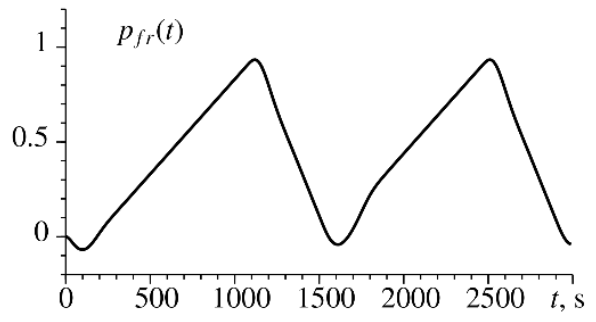

Fig. 3. Results of simulation of a deterministic system $\left(\mathrm{p}_{\mathrm{rg}}(\mathrm{t})=0\right)$.

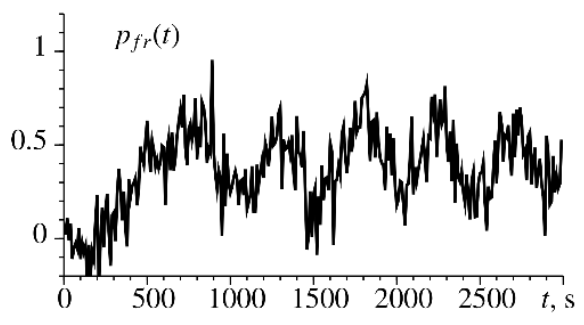

Fig. 4. Results of simulation under interference conditions $\left(\mathrm{p}_{\mathrm{rg}}(\mathrm{t})=10 \%\right)$.

influence of many external factors, it was impossible to qualitatively evaluate the degree of hoar frost formation directly on the basis of a pressure differential sensor. The measured value of the differential pressure in the actual system includes significant interference from the mechanical part of the recoperation system. This problem caused random switching between modes.

Transition process resulting from the simulation of a system with interference are shown in Fig. $4\left(\mathrm{p}_{\mathrm{rg}}(\mathrm{t})=10 \%\right)$. The results of the simulation reflect the reason for the unstable operation of the system as a whole, where untimely operation of the hysteresis element does not allow to ensure the efficiency of the recuperator. To solve this problem, the sensor can be represented in the form of differential equations or a dynamic model. Such a method of evaluation makes it possible to observe the tendency of the hoar frost formation process, due to the use of state variables. This solution will be efficient for the control systems with thawing, since the mathematical model of the process is not subject to interference from the mechanical part of the system.

\section{Observer of state variables of the hoar frost process}

The main factor affecting the process of hoar frost formation is the temperature of the environment. Thus, for a certain value of this parameter, the process of frost formation begins. In addition to the temperature of the outside air, the humidity of the air in the installation has a direct influence on the process of frost formation. In very dry air, the temperature of the frost can drop to $-30 \mathrm{C}$. And if the humidity is too moist, the temperature of the frosting hardly drops below the dew point temperature. This relationship between temperature and humidity was noticed during the operation of the automatic recuperation system in Yakutia (Russia). The main task of the presented model is to find the moment of 
switching from one mode to another, based on the value of the formed frost. In general, other values (humidity, pressure, e.t.c.) that affect the model have not been investigated, since they do not have a significant effect on switching moment calculation.

The main indicator influencing the hoar frost formation process is the temperature $\left(T_{\mathrm{fr}}\right)$ of the environment at which this process actually begins. For different objects this temperature can vary considerably. During the operation of the automatic recuperation system in Yakutia (Russia), a link was observed between the temperature ( $T_{\text {out }}$ ) and the humidity of the exhaust air. In particular, for dry outgoing air, the temperature $\left(\mathrm{T}_{\mathrm{fr}}\right)$ can drop to $-30 \mathrm{C}$, and also the rate of increase of hoar frost formation $\left(\mathrm{P}_{\mathrm{fr}}\right)$ falls off sensitively. And with moist air, the rate of frost rises with the temperature $\left(\left|T_{\text {out }}\right|\right)$. Fig. 2 presents structural diagram of the system with an observer of the state variables of the process of hoar frost. The upper part of the structural diagram is taken from Fig. 1. A reference model, is presented where the dynamic characteristics of the reference model differ from those adopted in the system. In particular, the rate of hoar frost formation is overestimated by a factor of two, and the time of inertia is increased by one third. In the system, the frostformation temperature adjustment circuit $\left(\mathrm{p}_{\mathrm{efr}}\right)$ is added, which includes a damping unit and a PID controller. The goal of a closed loop is to adjust a $\left(\mathrm{T}_{\mathrm{cmp}}\right)$ at which the damped mismatch tends to zero.

Stability and speed of the tuning loop can provide the optimal parameters of the PID controller. It is pssible by any available method adopted in the theory of automatic control. The transfer function of the open system was assumed in the following form

$$
W_{c l}(s)=\left(k_{p}+\frac{k_{i}}{s}+\frac{T_{d} s}{1+0.1 T_{d} s}\right) \frac{1}{s(1+s 10)(1+s 40)}
$$

where $\mathrm{k}_{\mathrm{p}}=50, \mathrm{k}_{\mathrm{i}}=0.1 \mathrm{~s}^{-1}, \mathrm{~T}_{\mathrm{d}}=10 \mathrm{~s}$.

In Fig. 5, the simulation results are presented in the corresponding structural scheme of Fig. 2.

As can be seen from the figure, the compensating value $\left(\mathrm{T}_{\mathrm{cmp}}\right)$ at the output of the PID controller should be $\mathrm{T}_{\mathrm{cmp}}=20^{\circ} \mathrm{C}$. But due to the fact that the parameters of the model are significantly different from the parameters of the object describing the process of a clogging an absolute coincidence is not observed. Nevertheless, the main purpose of solving the problems of false triggering of the hysteresis element is solved and it is possible to observe the restoration of the operation of the thawing circuit. Indeed, the processes of transition from regime to regime practically correspond to Fig. 3. and there are no false positives in them, which are observed in Fig. 4.

As a result, the structural diagram of the system with the observer of state variables of the degree of hoar frost formation provides a qualitative estimate of the actual degree of contamination over a sufficiently noisy value of the pressure drop across the heat exchanger. In Fig. 6 shows the correspondence of the pressure drop $\left(\mathrm{p}_{\mathrm{fr}}(\mathrm{t})-\right.$ dotted line $)$ and the evaluation of the degree of hoar frost formation $\left(\mathrm{p}_{\mathrm{efr}}(\mathrm{t})\right.$ - solid line $)$, which has a smooth character of change.

\section{Conclusion}

The article describes a solution for eliminating random switching in the system. This result is achieved by observing the trend of the incoming signal through the introduction of a damper. During operation, the control system has been able to cope with the tasks correctly. In highly specialized systems, problems may occur where measurement of non-trivial physical quantities is required to organize a process or an automatic system. These physical quantities can have quite understandable relationships with quantities that can be measured 
by standard sensors under external conditions and described in the form of differential equations.
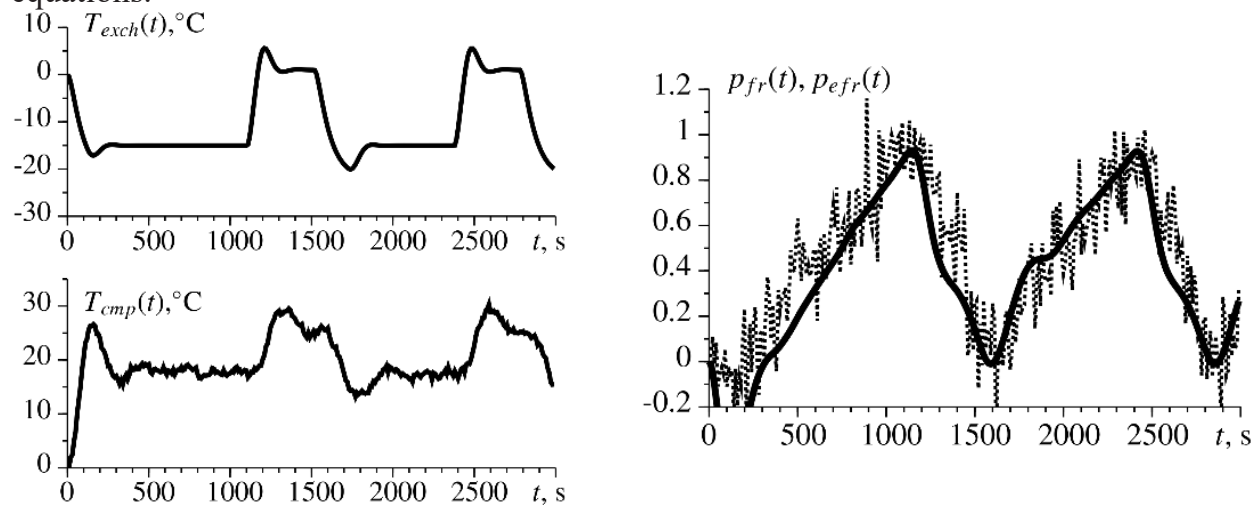

Fig. 5. The results of modeling using the state variable as the degree of hoar frost formation.

Fig. 6. Differential pressure and evaluation of the degree of hoar frost formation.

In such cases, a complex technique is required to estimate the value of a nontrivial physical quantity, taking into account both static and dynamic relationships. In these conditions it is quite difficult to find a suitable prototype of the solution in the scientific and technical literature. In this paper, a methodology for performing similar tasks is presented, which can be applied in other technological objects, where the measurement of non trivial physical quantities is required. Also, the material of the article can be useful to specialists in the field of synthesis of automatic recuperation systems.

\section{References}

1. M. Rafati Nasr, F. Fathieh, D. Kadylak, R. Huizing, R. Besant, C. Simonson, Exp. Therm. Fluid Sci. 77, 100 (2016)

2. K. Smith, S. Svendsen, Energy and Buildings, 107, 1 (2015)

3. A. Zandeckis, K. Klavina, M. Dzikevics, V. Kirsanovs, G. Zogla, J. Eng. Sci. Technol. Review, 8, 98 (2015)

4. B. Ouazia, R. Glazer, F. Szadkowski, C. Hoyme, Int. J. Ventilation, 14, 219 (2015)

5. S. Koziol, S. Zacharski, Solid State Phenom. 237, 148 (2015)

6. K. Allaerts, J. Al Koussa, J. Desmedt, R. Salenbien, Energy and Buildings, 138, 559 (2017)

7. A. Krofova, P. Kic, Eng. Rural Dev. 56 (2016)

8. F. Savrasov, S. Prokhorov, A. Shilin, J. Phys.: Conf. Series, 803 (2017)

9. A. Shilin, V. Bukreev, Commun. Comput. Inf. Sci. 487, 387 (2014) 